\title{
NILAI TUKAR PETANI PADI DAN BLEWAH DI DESA SAWOTRATAP KECAMATAN GEDANGAN KABUPATEN SIDOARJO
}

\author{
FARMERS EXCHANGE RATE OF RICE AND CANTALOUPE IN SAWOTRATAP \\ VILLAGE, GEDANGAN SUB-DISTRICT, SIDOARJO DISTRICT
}

\author{
NAFAKHATUL ASRIYAH, SUDIYARTO*, ENDANG YEKTININGSIH \\ Fakultas Pertanian, Universitas Pembangunan Nasional "Veteran" Jawa Timur \\ *E-mail : sudiyarto@upnjatim.ac.id
}

\begin{abstract}
ABSTRAK
Kesejahteraan petani merupakan kunci pembangunan pertanian. Nilai Tukar Petani dapat digunakan untuk mengukur kesejahteraan petani. Tujuan penelitian ini untuk mengukur besarnya Nilai Tukar Petani (NTP) padi dan blewah, seta perbandingan kesejahteraan antara petani padi dan blewah di Desa Sawotratap, Kecamatan Gedangan, Kabupaten Sidoarjo. Penelitian dilakukan kepada 38 responden petani yang mengusahakan usahatani padi dan blewah dalam satu tahun. Metode analisis data yang digunakan yaitu perhitungan Nilai Tukar Petani dan analisis deskriptif kuantitatif. Hasil dari penilitian ini menunjukkan rata-rata Nilai Tukar Petani padi yaitu sebesar $67,95 \%<100 \%$ dan rata-rata Nilai Tukar Petani blewah yaitu sebesar 215,24\% > 100\%. Apabila Nilai Tukar Petani kurang dari 100\% berarti harga yang diterima petani lebih rendah dari harga yang dibayar petani dan petani dikatakan kurang sejahterah. Artinya NTP padi lebih rendah dibandingkan dengan NTP blewah. Tingkat kesejahteraan petani saat melakukan usahatani padi pada musim hujan lebih rendah dari pada saat melakukan usahatani blewah pada musim kemarau. Sehingga perlu dilakukan berbagai upaya untuk meningkatkan Nilai Tukar Petani padi melalui penghematan penggunaan input produksi dan mengoptimalkan penggunaan tenaga kerja dalam keluarga petani, selain itu perlu adanya kerjasama dari pemerintah dalam hal penyediaan pupuk bersubsidi.
\end{abstract}

Kata Kunci: Nilai Tukar Petani (NTP), Kesejahteraan Petani, Pengeluaran, Penerimaan

\section{ABSTRACT}

Farmers' welfare is the key to agricultural development. Farmers Exchange Rate can be used to measure the welfare of farmers. The purpose of this study was to measure the farmer exchange rate (NTP) for rice and cantaloupe, as well as the comparison of welfare between rice and cantaloupe farmers in Sawotratap Village, Gedangan District, Sidoarjo Regency. The study was conducted on 38 farmer respondents who worked on rice and cantaloupe farming in one year. The data analysis method used is the calculation of Farmer Exchange Rate and quantitative descriptive analysis. The results of this study showed that the average exchange rate of rice farmers was $67.95 \%<100 \%$ and the average exchange rate of cantaloupe farmers was $215.24 \%>100 \%$. If the Farmer Exchange Rate is less than 100\%, it means that the price received by the farmer is lower than the price paid by the farmer and the farmer is said to be less prosperous. This means that the NTP of rice is lower than that of cantaloupe. The welfare level of farmers when doing rice farming in the rainy season is lower than when farming cantaloupe in the dry season. So it is necessary to make various efforts to increase the Exchange Rate of rice farmers through saving the use of production inputs and optimizing the use of labor in the farming family, besides that there is a need for cooperation from the government in terms of providing subsidized fertilizers.

Kewords: Farmer Exchange Rate (NTP), Farmer Welfare, Expenditure, Revenue

\section{PENDAHULUAN}

Sektor pertanian merupakan sektor utama penyumbang lapangan pekerjaan, memperoleh pendapatan bagi petani karena masyarakat Indonsesia sampai saat ini masih banyak yang bekerja di sektor 
pertanian. Sampai saat ini petani sebagai pelaku utama sektor pertanian masih memiliki tingkat kesejahteraan yang tergolong rendah. Kesejahteraan petani perlu mendapat perhatian karena terdapat indikasi kesejahteraan petani menurun akibat ketidakseimbangan antara hasil jual produk pertanian terhadap besarnya kebutuhan keluarga petani (Dauda 2019). Apabila kesejahteraan petani tergolong rendah, maka petani masuk dalam kategori masyarakat yang kurang mampu (Setiawan et al. 2018). Peningkatan produktivitas dapat meningkatkan pendapatan sehingga membantu mengurangi kemiskinan petani (Abdullah dkk., 2019).

Usahatani menjadi sumber lapangan kerja dan pendapatan sehari-hari masyarakat yang tinggal di pedesaan, maka diperlukan pengelolaan yang sesuai dengan menghemat penggunaan faktor produksi (Handayani, Irwan, and Begem 2017). Kemampuan petani dalam berusahatani dapat dilihat melalui besarnya Nilai Tukar Petani yang dapat menjadi indikator ukuran kesejahteraan petani (Yacoub and Mutiaradina 2020). NTP merupakan rasio harga yang diterima oleh petani dengan harga yang dibayar oleh petani dan dinyatakan dalam persentase. NTP menjadi ukuran mampu tidaknya petani membeli barang atau jasa dari produk usahatani yang dihasilkan dan membiayai seluruh keperluan petani untuk kebutuhan usahatani (Badan Pusat Statistik Provinsi Jawa Timur, 2020). Semakin tinggi NTP maka tingkat kesejahteraan petani semakin tinggi pula.

Semakin rendah NTP menunjukkan bahwa kesejahteraan petani menurun dan pendapatan petani berkurang. Penurunan NTP disebabkan oleh peningkatan harga hasil produksi usahatani tidak bisa melampaui harga komoditas yang diperlukan petani untuk kebutuhan konsumsi rumah tangga, biaya produksi usahatani, penambahan barang modal di pertanian (Palengkahu, Laoh, and Pangemanan 2019).

Nilai Tukar Petani akan mengalami fluktuasi berdasarkan tinggi rendahnya penerimaan dan pengeluaran petani. Apabila penerimaan petani lebih tinggi dibandingkan pengeluarkan maka besarnya NTP akan mengalami peningkatan (Pettalolo, Antara, and Damayanti 2019). NTP menggambarkan kemampuan petani dakam membeli keperluan produksi pertanian dan kebutuhan konsumsi keluarga petani (Rachmat 2013).

Semakin tinggi NTP yang dihasilkan maka akan semakin baik kemampuan petani dalam membeli suatu produk (Putri and Noor 2018). Peningkatan pendapatan 
dan produksi komoditas petanian belum tentu dapat membuat kesejahteraan petani mengalami peningkatan, apabila tidak diikuti oleh peningakatan daya beli petani (Saleh 2020). Tinggi rendahnya NTP dipengaruhi oleh beberapa faktor yaitu luas lahan, tingkat produksi, harga jual produk pertanian, biaya produksi, dan biaya konsumsi pangan dan non pangan. Peningkatan luas lahan dan produksi dapat menyebabkan bertambahnya pendapatan petani, sehingga dapat meningkatkan kesejahteraan dan keuntungan bagi petani (Amanullah et al. 2020). Harga merupakan atribut sensitif yang mempengaruhi keberlanjutan usahatani dan dapat mempengaruhi pendapatan petani (Frimawaty et al. 2013). Biaya produksi usahatani berupa semua pengeluaran untuk benda maupun jasa yang dibutuhkan dalam satu kali musim tanam (Wasirin 2016). Pengeluaran konsumsi pangan dan non pangan mampu mengukur tingkat kesejahteraan penduduk (Badan Pusat Statistik 2017).

Tabel 1. Perkembangan Nilai Tukar Petani Jawa Timur Tahun 2018-2019

\begin{tabular}{ccc}
\hline No & Tahun & NTP (\%) \\
\hline 1 & 2018 & 101,45 \\
2 & 2019 & 103,32 \\
3 & 2020 & 100,80 \\
\hline
\end{tabular}

Sumber : Badan Pusat Statistik Provinsi Jawa Timur Tahun 2020
Berdasarkan tabel 1 menurut data Badan Pusat Statistik Provinsi Jawa Timur (2020), perkembangan NTP Jawa Timur Tahun 2018-2020 cenderung mengalami penurunan. Penurunan NTP secara drastis terjadi pada rentang bulan Januari hingga bulan Juni. Fluktuasi NTP tersebut dapat diartikan bahwa tingkat pendapatan usahatani petani mengalami peningkatan dan penurunan yang tidak stabil. Perbaikan dan peningkatan NTP sangat diperlukan agar kesejahteraan petani meningkat dan mampu mencukupi kebutuhan rumah tangganya. Kesejahteraan petani dapat direalisasikan melalui peningkatan pendapatan usahatani, minimnya kegagalan panen, meningkatnya produktivitas, dan harga jual produk pertanian tinggi (Keumala and Zainuddin 2018). Kesejahteraan terdiri dari kesejahteraan secara ekonomi dan kesejahteraan secara sosial (Matina and Praza 2018). Berdasarkan ekonomi rumah tangga, hasil dari perhitungan pengeluaran dan pendapatan rumah tangga bisa digunakan untuk mengetahui kesejahteraan petani (Fahmi and Rusyadi 2020).

Menurut data (Badan Pusat Statistik Provinsi Jawa Timur, 2020), pada tahun 2019 Kabupaten Sidoarjo menjadi Kabupaten yang memiliki produktivitas padi paling tinggi di Jawa Timur kedua 
setelah Kota Malang. Kabupaten Sidoarjo merupakan daerah pertanian perkotaan, dimana petani hanya dapat menanam beberapa komoditas tertentu dengan menyesuaikan lokasi, cuaca, serta iklim yang cocok. Kabupaten Sidoarjo terdiri dari 18 Kecamatan yang mayoritas petaninya mengusahakan tanaman pangan padi dan tanaman hortikultura. Blewah adalah salah satu tanaman hortikultura yang banyak ditanam petani di Kabupaten Gedangan. Blewah adalah tanamana hortikultura yang ditanam secara musiman, sehingga biasanya petani akan menanam blewah setelah selesai usahatani padi. (Jannah and Santosa 2019).

Desa Sawotratap, Kecamatan Gedangan merupakan lokasi produksi blewah dengan kualitas terbaik di Kabupaten Sidoarjo. Petani di Desa Sawotratap mayoritas mengusahakan blewah saat musim kemarau, dan mengusahakan padi saat musim hujan. Petani di Desa Sawotratap biasanya menanam 2 komoditas selama 1 tahun dikarenakan pengairannya menggunakan sistem tadah hujan. Perhitungan Nilai Tukar Petani diperlukan untuk mengetahui mengetahui apakah petani perkotaan bisa mencukupi kebutuhan sehari-hari dari hasil usahatani dan untuk mengetahui perbandingan NTP padi dan blewah dalam masa tanam 1 tahun. Tujuan dari penelitian ini adalah untuk mengetahui besarnya Nilai Tukar Petani saat menanam padi dan blewah di Desa Sawotratap, serta mengetahui perbandingan kesejahteraan antara petani padi dan blewah. Manfaat penelitian ini yaitu dapat menjadi gambaran untuk petani padi dan blewah agar bisa mengembangkan dan mengelola usahataninya, serta dapat mengoptimalkan sumber daya yang ada untuk mencapai kesejahteraan petani. Selain itu juga bisa dijadikan bahan informasi tambahan bagi pemerintah daerah setempat dalam membuat kebijakan untuk upaya peningkatan kesejahteraan petani padi dan blewah.

\section{METODE PENELITIAN}

Penelitian dilakukan pada bulan Maret 2021 di Desa Sawotratap, Kecamatan Gedangan, Kabupaten Sidoarjo, Provinsi Jawa Timur. Penentuan lokasi penelitian dilakukan berdasarkan pertimbangan bahwa lokasi tersebut merupakan daerah produksi padi dan blewah dalam masa tanam satu tahun, dan merupakan wilayah pertanian yang berada di perkotaan. Populasi yang digunakan adalah seluruh anggota dari Gabungan Kelompok Tani (Gapoktan) Desa Sawotratap sebanyak 60 petani padi dan blewah. Penentuan jumlah sampel petani 
dilakukan menggunakan perhitungan rumus slovin dengan menggunakan tingkat kesalahan $10 \%$ sehingga mendapatkan jumlah sampel sebanyak 38 petani yang mengusahakan tanaman padi dan blewah. Teknik pengambilan sampel dilakukan menggunakan metode simple random sampling yaitu pengambilan sampel dengan cara menganggap setiap populasi bisa menjadi sampel penelitian.

Pengumpulan data penelitian diperoleh dari data primer dan data sekunder. Data primer dari hasil observasi dilapangan dan wawancara secara lansung dengan petani padi dan blewah menggunakan kuisioner terbuka yang telah disiapkan oleh penulis. Sedangkan data sekunder diperoleh dari publikasi, studi literatur, jurnal, dan beberapa pustaka lainnya, serta lembaga/instansi lainnya yaitu Badan Pusat Statistik dan Badan Penyuluhan Pertanian yang mampu melengkapi data primer.

Analisis data dilakukan melalui perhitungan Nilai Tukar Petani yang kemudian dianalisis dengan analisis deskriptif kuantitatif untuk mengetahui kesejahteraan petani yang menanam padi dan blewah. Secara konseptual perhitungan Nilai Tukar Petani dapat dihitung menggunakan rumus konsep pendapatan yaitu sebagai berikut :

$$
\mathrm{NTP}=\frac{\mathrm{TR}}{\mathrm{TC}+\mathrm{Ct}} \times 100 \%
$$

Keterangan:

NTP = Nilai Tukar Petani $(\%)$

$\mathrm{TR}=$ Total Penerimaan $(\mathrm{Rp} / \mathrm{MT})$

$\mathrm{TC}=$ Total Biaya Usahatani $(\mathrm{Rp} / \mathrm{MT})$

$\mathrm{Ct}=$ Total pengeluaran konsusmsi rumah tangga petani $(\mathrm{Rp} / \mathrm{MT})$

Berdasarkan rumus tersebut dapat disimpulkan bahwa Nilai Tukar Petani dapat dihitung menggunakan rumus sebagai berikut:

$$
\mathrm{NTP}=\frac{\mathrm{HT}}{\mathrm{HB}} \times 100 \%
$$

Keterangan:

NTP = Nilai Tukar Petani $(\%)$

$\mathrm{HT}=$ Harga yang diterima Petani (Rp)

$\mathrm{HB}=$ Harga yang dibayar Petani $(\mathrm{Rp})$

Setelah diperolah hasil Nilai Tukar Petani masing-masing petani lalu membandingkan kesejahteraan petani saat menanam padi dan blewah di Desa Sawotratap, Kecamatan Gedangan, Kabupaten Sidoarjo. NTP yang diperoleh kemudian dianalisis menggunakan metode deskriptif kuantitatif dengan kriteria berdasarkan tingkat kesejahteraan petani menurut Badan Pusat Statistik Provinsi Jawa Timur (2020) besarnya nilai NTP sebagai berikut:

a. NTP > 100, dapat diartikan petani sejahterah atau surplus. 
b. NTP $=100$, dapat diartikan tingkat kesejahteraan petani tetap dan tidak berubah atau impas/break even.

c. NTP $<100$, dapat diartikan petani kurang sejahterah atau defisit.

\section{HASIL DAN PEMBAHASAN}

Nilai Tukar Petani (NTP) menjadi indikator yang mengukur kemampuan tukar produk usahatani yang dihasilkan petani dengan berbagai produk sesuai dibutuhkan rumah tangga petani. Nilai Tukar Petani dihitung dengan membandingkan antara penerimaan dengan pengeluaran. Petani Desa Sawotratap menanam 2 komoditas dalam satu tahun, yaitu komoditas tanaman pangan berupa padi dan komoditas tanaman hortikultura berupa blewah. Nilai Tukar Petani padi dan blewah dihitung dengan tujuan untuk membandingkan kemampuan petani dalam mencukupi kebutuhan keluarganya saat musim tanam padi dan blewah. NTP dapat diketahui melalui besarnya penerimaan hasil usahatani dan pengeluaran berupa biaya produksi pertanian dan biaya konsumsi petani per musim tanam padi dan blewah. Berikut merupakan data Nilai Tukar Petani padi dan blewah di Desa Sawotratap.

\begin{tabular}{ccccc} 
Tabel & 2. Nilai Tukar Petani Padi dan \\
& \multicolumn{4}{c}{ Blewah Desa sawotratap } \\
\hline $\begin{array}{c}\text { Komo } \\
\text { ditas }\end{array}$ & $\begin{array}{c}\text { Penerimaan } \\
\text { (Rp) }\end{array}$ & $\begin{array}{c}\text { Pengeluaran } \\
\text { Biaya } \\
\text { produksi } \\
\text { (Rp) }\end{array}$ & $\begin{array}{c}\text { Bonsumsi } \\
\text { Konsu) }\end{array}$ & $\begin{array}{c}\text { NTP } \\
\text { (\%) }\end{array}$ \\
\hline Padi & 12.031 .579 & 8.836 .839 & 9.134 .200 & 67,95 \\
Blewah & 42.105 .263 & 14.617 .943 & 5.463 .782 & 215,24 \\
\hline
\end{tabular}

Sumber: Data Primer diolah

Berdasarkan Tabel 2 diketahui bahwa besarnya rata-rata Nilai Tukar Petani saat menanam padi yaitu sebesar $67,95 \%$ dan rata-rata Nilai Tukar Petani saat menanam blewah yaitu sebesar 215,24 $\%$. Nilai tersebut menunjukkan bahwa NTP blewah lebih tinggi dari pada NTP padi. Rata-Rata Nilai Tukar Petani padi Desa Sawotratap yaitu sebesar 67,95 \% dengan penerimaan sebesar Rp. 12.031.579 dan pengeluaran petani sebesar Rp. 17.971.039. Penerimaan petani padi lebih rendah dari pada pengeluaran petani. Sehingga petani tidak dapat mengandalkan hasil dari usahatani padi untuk mencukupi kebutuhan keluarganya. Rata-rata Nilai tukar Petani Blewah Desa Sawotratap yaitu sebesar 215,24\% dengan penerimaan sebesar Rp. 42.105.263 dan pengeluaran sebesar Rp. 20.081.724. Penerimaan petani blewah lebih tinggi dari pengeluaran petani. Artinya petani mampu mencukupi seluruh kebutuhan rumah tangganya saat berusahatani blewah. Besarnya pendapatan petani mempengaruhi pola konsumsi petani untuk mengalokasikan 
pendapatannya dalam memenuhi kebutuhan pangan dan non pangan (Prasetyoningrum, Rahayu, and Marwanti 2016).

Petani menanam 2 komoditas padi dan blewah dengan alasan untuk memanfaatkan lahan yang ada dan untuk mencukupi kebutuhan rumah tangga tani. Jika hanya mengandalkan usahatani padi belum cukup untuk mencukupi kebutuhan sehari-hari. Petani menanam blewah karena hasil pendapatan dari usahatani blewah jauh lebih tinggi dibandingkan padi. Biasanya petani menggabungkan pendapatan padi dan blewah untuk mencukupi kebutuhan rumah tangganya selama 1 tahun dan sebagian disimpan untuk biaya produksi pada musim tanam selanjutnya.

Kesejahteraan petani padi dan blewah dapat diketahui berdasarkan besarnya Nilai Tukar Petani masingmasing komoditas tersebut. Semakin tinggi Nilai Tukar petani, maka semakin tinggi tingkat kesejahteraannya. Indikator kesejahteraan petani ditunjukkan dari nilai NTP, apabila NTP>100 maka petani dikatakan sejahtera dan mampu mencukupi kebutuhan rumah tangganya. Sedangkan apabila NTP<100 maka petani dikatakan kurang sejahterah dan belum mampu mencukupi kebutuhan rumah tangganya.
Berikut merupakan distribusi Nilai Tukar Petani padi dan blewah di Desa Sawotratap.

Distribusi Nilai Tukar Petani Padi Desa Sawotratap, Kecamatan Gedangan, Kabupaten Sidoarjo

Tabel 3. Distribusi Nilai Tukar Petani Padi Desa Sawotratap

\begin{tabular}{cccc}
\hline No & $\begin{array}{c}\text { NTP } \\
(\boldsymbol{\%})\end{array}$ & $\begin{array}{c}\text { Jumlah (RT } \\
\text { Petani) }\end{array}$ & $\begin{array}{c}\text { Persentase } \\
(\boldsymbol{\%})\end{array}$ \\
\hline 1 & $<100$ & 36 & 94,7 \\
2 & 100 & 0 & 0 \\
3 & $>100$ & 2 & 5,3 \\
\hline \multicolumn{2}{c}{ Jumlah } & 38 & 100 \\
\hline
\end{tabular}

Sumber: Data Primer diolah

Berdasarkan Tabel 3 diketahui bahwa dari 38 responden petani padi hanya terdapat 2 petani yang memiliki NTP> 100 atau dengan persentase sebesar 5,3\%. Sisanya sebanyak 36 petani memiliki NTP<100 atau sebesar 94,7\%. Angka tersebut menunjukkan bahwa mayoritas pendapatan petani saat melakukan usahatani padi lebih kecil dari pada pengeluarannya. Petani padi di Sawotratap dikatakan kurang sejahterah karena tidak mampu mencukupi kebutuhan usahatani dan rumah tangganya selama 3,5 bulan apabila hanya mengandalkan hasil dari usahatani padi. Meskipun hasil usahatani padi lebih rendah dibandingkan dengan blewah, petani tetap mengusahakannya untuk menambah penghasilan. Faktor- 
faktor yang menyebabkan rendahnya NTP petani padi Desa Sawotratap yaitu penggunaan pupuk dan obat-obatan yang berlebihan, kurangnya keterampilan dalam berusahatani dan masih timbul rasa gengsi untuk menggarap sawah karena tinggal di daerah perkotaan sehingga lebih banyak menggunaan tenaga kerja dari luar keluarga (buruh tani) yang berasal dari luar daerah, selain itu petani di Desa Sawotratap tergolong petani yang konsumtif karena pengeluaran konsumsi untuk kebutuhan pangan lebih tinggi dari pada non pangan. Sehingga menyebabkan rata-rata Nilai Tukar Petani padi di Desa Sawotratap rendah dan petani kurang sejahterah. Apabila semua faktor produksi dimanfaatkan dengan baik akan meningkatkan produksi secara maksimal (Tola 2020).

Distribusi Nilai Tukar Petani Padi Desa Sawotratap, Kecamatan Gedangan, Kabupaten Sidoarjo

Tabel 4. Distribusi Nilai Tukar Petani Padi Desa Sawotratap

\begin{tabular}{cccc}
\hline No & $\begin{array}{c}\text { NTP } \\
(\boldsymbol{\%})\end{array}$ & $\begin{array}{c}\text { Jumlah (RT } \\
\text { Petani) }\end{array}$ & $\begin{array}{c}\text { Persentase } \\
(\boldsymbol{\%})\end{array}$ \\
\hline 1 & $<100$ & 0 & 0 \\
2 & 100 & 0 & 0 \\
3 & $>100$ & 38 & 100 \\
\hline \multicolumn{2}{c}{ Jumlah } & 38 & 100 \\
\hline
\end{tabular}

Sumber: Data Primer diolah

Berdasarkan Tabel 4 diketahui bahwa sebanyak 38 responden petani blewah memiliki NTP>100 atau dengan persentase sebesar $100 \%$. Tidak ada petani blewah yang memiliki NTP $<100$. Artinya komoditas blewah merupakan komoditas yang menguntungkan untuk ditanam petani karena seluruh petani mengalami surplus atau penerimaan usahatani lebih besar dibandingkan dengan pengeluaran usahatani dan pengeluaran rumah tangga tani. Hal tersebut menunjukkan bahwa seluruh petani blewah dapat dikatakan sudah sejahterah dan mampu mencukupi kebutuhan keluarganya. Petani juga mempunyai kemampuan daya beli yang cukup untuk kebutuhan usahataninya. Blewah menjadi komoditas yang paling menguntungkan bagi petani karena blewah di Desa Sawotratap menjadi blewah unggulan di Kabupaten Sidoarjo, sehingga harga jual blewah relatif tinggi dari pada daerah lain. Selain itu hasil produksi blewah juga tinggi karena lahan sawah di Desa Sawotratap sangat cocok untuk ditanami blewah.

Cara yang dilakukan petani untuk mengoptialkan hasil panen blewah yaitu dengan melakukan perawatan yang intensif. Mulai dari penggunaan pupuk dan pestisida yang optimal, pengendalian HPT yang dilakukan berkala, bahkan beberapa petani rela tidak bekerja sampingan saat musim tanam blewah untuk merawat dan 
mengontrol tanaman blewahnya. Selain itu blewah merupakan tanaman hortikultura yang dapat dipanen berkali-kali tergantung tingkat kematangannya selama 14 hari sampai tanaman tidak berbuah lagi. Hal tersebut yang membuat petani blewah mampu menghasilkan pendapatan yang lebih tinggi dari padi. Sehingga Nilai Tukar Petani blewah lebih tinggi dibandingkan Nilai Tukar Petani padi.

\section{KESIMPULAN DAN SARAN}

\section{Kesimpulan}

Nilai Tukar Petani (NTP) petani padi dan blewah diperoleh melalui perhitungan penerimaan dan pengeluaran petani. NTP padi di Desa Sawotratap lebih rendah dari pada NTP blewah yaitu sebesar 67,95\% atau $<100 \%$, sedangkan NTP blewah yaitu sebesar 215,24\% atau > $100 \%$. Artinya petani di Desa Sawotratap, Kecamatan Gedangan, Kabupaten Sidoarjo lebih sejahterah dan mampu mencukupi kebutuhan rumah tangganya saat menanam blewah dari pada padi.

\section{Saran}

Nilai Tukar Petani (NTP) padi di Desa Sawotratap dapat ditingkatkan melalui kerjasama petani dan pemerintah. Petani seharusnya menggunakan sarana produksi pertanian secukupnya dan tidak berlebihan, lebih mengoptimalkan tenaga kerja dalam keluarga bagi petani yang tidak memiliki pekerjaan sampingan, menggunakan teknologi berupa ramalan cuaca untuk mengetahui frekuensi hujan untuk mengantisipasi terjadinya banjir dan gagal panen. Pemerintah seharusnya mempermudah petani dalam pembelian pupuk dengan menyediakan pupuk subsidi sesuai dengan jumlah yang dibutuhkan petani. Karena salah satu masalah utama yang dialami petani di Desa Sawotratap yaitu minimnya pasokan pupuk bersubsidi, sehingga petani harus mengupayakan pupuk non subsidi yang sulit untuk dibeli dan memiliki harga yang lebih mahal . Sehingga Nilai Tukar Petani padi di Sawotratap dapat meningkat.

\section{DAFTAR PUSTAKA}

Amanullah, Ghulam Rasool Lakhan, Siraj Ahmed Channa, Habibullah Magsi, Mansoor Ahmed Koondher, Jing Wang, and Naseer Ahmed Channa. 2020. "Credit Constraints and Rural Farmers' Welfare in an Agrarian Economy." Heliyon 6 (10). https://doi.org/10.1016/j.heliyon.20 20.e05252.

Badan Pusat Statistik. 2017. Pengeluaran Untuk Konsumsi Penduduk Indonesia. https://www.bps.go.id/.

Badan Pusat Statistik Provinsi Jawa Timur. 2020a. Perkembangan Indeks Harga Konsumen Jawa Timur. https://jatim.bps.go.id.

2020b. Provinsi Jawa Timur 
Dalam Angka 2020. https://jatim.bps.go.id. . 2020c. Statistik Nilai Tukar Petani Provinsi Jawa Timur 2019. https://jatim.bps.go.id.

Dauda, Adidjoyo. 2019. "Faktor Yang Mempengaruhi Nilai Tukar Petani Sektor Tanaman Pangan Di Provinsi Sulawesi Tengah." Jurnal Pembangunan Daerah 1(2) (2019 (2): 49-56.

Fahmi, Moh Farih, and Refki Rusyadi. 2020. "Makna Kesejahteraan Bagi Keluarga Petani Di Kabupaten Lamongan.” Jurnal Ekonomi Dan Studi Kebijakan 1 (1).

Frimawaty, Evi, Adi Basukriadi, Jasmal A. Syamsu, and T.E. Budhi Soesilo. 2013. "Sustainability of Rice Farming Based on Eco-Farming to Face Food Security and Climate Change: Case Study in Jambi Province, Indonesia." Procedia Environmental Sciences 17: 53-59. https://doi.org/10.1016/j.proenv.20 13.02.011.

Handayani, Siti Asih, Effendi Irwan, and Viantimala Begem. 2017. "Produksi Dan Pendapatan Usahatani Padi Di Desa Pujo Asri Kecamatan Trimurjo Kabupaten Lampung Tengah." JIIA 5 (4): 422-29.

Jannah, Hulwatun Raudatil, and Ribut Santosa. 2019. "Analisis Usahatani Blewah (Cucurbita Melo) Di Desa Gapura Barat Kecamatan Gapura Kabupaten Sumenep." Prosiding: Seminar Nasional Optimalisasi Sumber Daya Lokal Di Era Revolusi Industri 4.0, 450-57.

Keumala, Cut Muftia, and Zamzami Zainuddin. 2018. "Indikator
Kesejahteraan Petani Melalui Nilai Tukar Petani ( NTP ) Dan Pembiayaan Syariah Sebagai Solusi." Economica: Jurnal Ekonomi Islam 9 (1): 129-49.

Matina, and Riyandhi Praza. 2018. "Analisis Tingkat Kesejahteraan Petani Padi Sawah Di Kabupaten Aceh Utara." Jurnal AGRIFO 3 (2).

Palengkahu, Julietta Christi, Olly Esry Harryani Laoh, and Paulus Adrian Pangemanan. 2019. "Nilai Tukar Petani Padi Sawah Di Kecamatan Tompaso Baru Kabupaten Minahasa Selatan." Journal of Chemical Information and Modeling 53 (9): 1689-99.

Pettalolo, Adhe Risya, Made Antara, and Lien Damayanti. 2019. "FaktorFarktor Yang Mempengaruhi Nilai Tukar Petani Padi Sawah Di Desa Sidondo I Kecamatan Sigi Biromaru Kabupaten Sigi." Jurnal Agrotekbis 7 (4): 485-94. https://jatim.bps.go.id.

Prasetyoningrum, Fajar, Endang Siti Rahayu, and Sri Marwanti. 2016. "Analisis Pola Konsumsi Rumah Tangga Petani Jagung Di Kabupaten Grobogan." AGRIC Jurnal Ilmu Pertanian 28 (1 \& 2): $41-54$.

Putri, Citra Kurnia, and Trisna Insan Noor. 2018. "Analisis Pendapatan Dan Tingkat Kesejahteraan Rumah Tangga Petani Padi Sawah Berdasarkan Luas Lahan Di Desa Sindangsari, Kecamatan Banjarsari, Kabupaten Ciamis, Provinsi Jawa Barat." Jurnal Ilmiah Mahasiswa AGROINFO GALUH 4 (3): 92735 .

Rachmat, Muchjidin. 2013. "Nilai Tukar Petani : Konsep, Pengukuran, Dan 
Relevansinya Sebagai Indikator Kesejahteraan Petani." Jurnal Agro Ekonomi 31 (2): 111-22.

Saleh, Leni. 2020. “Analisis Nilai Tukar Dan Pengeluaran Rumah Tangga Petani Padi Sawah Di Kabupaten Konawe." Journal of Chemical Information and Modeling 9 (9): 1689-99.

Setiawan, Rizkya Adzhura Puteri, Trisna Insan Noor, Lies Sulistyowati, and Iwan Setiawan. 2018. "Analisis Tingkat Kesejahteraan Petani Kedelai Dengan Menggunakan Pendekatan Nilai Tukar Petani ( Ntp ) Dan Analysis the Prosperity of Soybean Farmers Using Approach Exchange Farmers Rate ( Ntp ) and Exchange Household Income ( Ntprp ).” Jurnal Agribisnis Terpadu 12 (2): 178-89. https://jurnal.untirta.ac.id/index.php /jat/article/download/6779/4702.

Tola, Elisabeth Cynthia M. 2020. "FaktorFaktor Yang Mempengaruhi Produksi Melon Golden (Cucumis Melo L) Di Kota Cilegon.” Jurnal Ilmu Pertanian Tirtayasa 2 (1): 110-21.

Wasirin. 2016. “Analisis Usahatani Padi Sawah Dengan Pendekatan Pengelolaan Tanaman Terpadu Di Kecamatan Kebasen." Agritech XVIII (1): 39-47.

Yacoub, Yarlina, and Hana Mutiaradina. 2020. "Analisis Kesejahteraan Petani Dan Kemiskinan Perdesaan Di Indonesia." Prosiding Seminar Akademik Tahunan Ilmu Ekonomi Dan Studi Pembangunan, 92-102. 